\title{
Rheumatic heart disease in the South West region of Cameroon: a hospital based echocardiographic study
}

\author{
Clovis Nkoke ${ }^{1,2^{*}}$, Anastase Dzudie $^{2,3}$, Christelle Makoge ${ }^{2}$, Engelbert Bain Luchuo ${ }^{4}$, Ahmadou Musa Jingi ${ }^{2}$ \\ and Samuel Kingue ${ }^{2}$
}

\begin{abstract}
Objective: Rheumatic heart disease (RHD) prevails as a major public health problem in sub-Saharan Africa. In Cameroon, reports on RHD have been so far limited to a few cities. We sought to describe the demographic, clinical and echocardiographic features of rheumatic heart disease in the Buea Regional Hospital, South West region of Cameroon. Echocardiography reports between June 2016 and June 2017 were reviewed. The diagnosis of RHD was based on the World Heart Federation Criteria for the diagnosis of RHD.

Results: A total of 669 echocardiograms were performed over the 1 year study period. Twenty-one (3.1\%) had a definite echocardiographic diagnosis of RHD. There were 14 (66.7\%) females. The age range was 13-94 years with a mean age of $47.8 \pm 20.3$ years. The most common indications for echocardiography were heart failure (47.6\%), and dyspnea (42.9\%). The mitral valve was the most commonly affected valve in $80.9 \%$ of cases. The most common valve lesion was isolated mitral stenosis (42.9\%), followed by isolated mitral regurgitation (28.6\%). There were no lesions on the tricuspid and pulmonic valves. Severe lesions were found in $80.9 \%$ of the patients. The complications were pulmonary hypertension (66.7\%) and atrial fibrillation (9.5\%).
\end{abstract}

Keywords: Rheumatic heart disease, South West region, Cameroon

\section{Introduction}

Rheumatic heart disease (RHD) is a major public health problem in low and middle income countries where it continues to claim the lives of many children and young adults [1-4]. It is a leading cause of heart failure in children and young adults in sub-Saharan Africa $[1,5]$.

Rheumatic heart disease results from repeated episodes of acute rheumatic fever (ARF) following a group A streptococcal throat infection. There are about 15.6 million cases of ARF/RHD worldwide, with about 233,000 deaths yearly mostly in children and young adults in developing countries $[2,3]$. Deaths from rheumatic heart disease results from complications such as heart failure, cardio-embolic stroke, atrial fibrillation, pulmonary

\footnotetext{
*Correspondence: cnkoke@yahoo.com

${ }^{2}$ Faculty of Medicine and Biomedical Sciences, University of Yaounde 1, Yaounde, Cameroon

Full list of author information is available at the end of the article
}

hypertension, pregnancy related complications and complications related to surgery. Treatment of advanced rheumatic heart disease requires surgery which is inaccessible in resource limited settings. It is a disease that is preventable.

The prevalence of RHD varies from one country to another and even within the same country. In Nigeria, the prevalence has been shown to range from 3.7 to $38.5 \%$ [6-9], with some authors reporting a decline in the prevalence of RHD. This decline in RHD prevalence was attributed to improvements in the socio-economic condition and increased access to antibiotics for the treatment of sore throat [10]. In Cameroon, reports of Rheumatic heart disease have so far been limited to a few cities. We sought to describe for the first time the demographic and echocardiographic pattern of RHD in the South West region of Cameroon. 


\section{Main text \\ Methods \\ Study design and setting}

This was a cross-sectional study conducted in the Buea Regional Hospital, South West region of Cameroon. The echocardiography register was surveyed from June 2016 to June 2017. All echocardiograms of patients with diagnosis of Rheumatic heart disease were reviewed. RHD diagnosis was based on the World Heart Federation (WHF) criteria for echocardiographic diagnosis of RHD. Briefly, RHD was defined by the presence of any evidence of mitral or aortic regurgitation seen in two planes associated with at least two of the following morphologic abnormalities of the regurgitating valve: restricted leaflet motility, focal or generalized valvular thickening, and abnormal sub-valvular thickening [11]. The echocardiographic reports were reviewed and used as the basis of RHD diagnosis. The echocardiography machine used was a Sonoscape $\mathrm{S} 8^{\circledR}$.

Only reports with sufficient information to make the diagnosis of RHD by the WHF criteria were included. Those with isolated functional regurgitating lesions were excluded from the analysis. Data were summarized by the type of valves involved, pathology (i.e., stenosis vs. regurgitation). Severity of valve lesions was described as mild, moderate, and severe according to American College of Cardiology/American Heart Association (ACC/AHA) guidelines [12]. Pulmonary hypertension was defined as a mean pulmonary artery pressure $>35 \mathrm{mmHg}$. Demographic and clinical data collected included age, sex and indication of echocardiography. The study was approved by the administrative authorities of the hospital acting as the local ethics committee. No formal ethics approval was required in this particular case.

\section{Statistical analysis}

Data were analyzed using SPSS version 22 for Windows. The results were presented as count and percentage for qualitative variables, and means and standard deviation for quantitative variables.

\section{Results \\ Demographic characteristics and indications of echocardiography}

During the study period, a total of 669 echocardiographic examinations were performed. Twenty-one (3.1\%) had a definite echocardiographic diagnosis of RHD. There were $16(66.7 \%)$ females. The age range was $13-94$ years with a mean age of $47.8 \pm 20.3$ years. There was no significant age difference between males and females (40.8 vs. 51.3 years, $\mathrm{p}=0.28$ ). The most common indications for echocardiography were heart failure (47.6\%), and dyspnea (42.9\%). Other indications for echocardiography were palpitations (4.8\%) and atrial fibrillation (4.8\%).

\section{Pattern of valve lesions}

The mitral valve was the most commonly affected valve in $80.9 \%$ of cases. The most common valve lesion was isolated mitral stenosis (42.9\%) followed by isolated mitral regurgitation (28.6\%) (Table 1). Mitral stenosis was more common in females (66.7\%) than males but the difference was not significant $(p=1.00)$. Severe lesions were found in $80.9 \%$ of the patients. The complications were pulmonary stenosis (66.7\%) and atrial fibrillation (9.5\%).

\section{Discussion and conclusions}

This is the first report on rheumatic heart disease from the South West region of Cameroon. In this study of echocardiography, we have shown that rheumatic disease affects $3.1 \%$ of patients referred for echocardiography. Heart failure and dyspnea were the most common indications of echocardiography. The mitral valve was the most commonly affected valve. The most frequent rheumatic valve lesion was isolated mitral stenosis followed by isolated mitral regurgitation. The tricuspid and pulmonic valves were not affected. More than two-third of rheumatic valve lesions were severe. The majority of the patients presented with complications.

A hospital based echocardiographic study in Yaounde covering a decade of activities showed that rheumatic heart disease affected about $6 \%$ of children aged $\leq 18$ years referred for echocardiography [13]. The prevalence of $3.1 \%$ reported in our study is close to the $3.7 \%$ reported by Ogah et al. in Nigeria [6]. In the Nigerian Savannah, the prevalence of RHD was $9.8 \%$ in a hospital based echocardiographic study covering a period of 4 years [14]. The prevalence of RHD varies from one country to another and even within the same country. This can be due to differences in regions and mode of selection of patients. To the best

Table 1 Distribution of valvular lesions

\begin{tabular}{ll}
\hline Valvular lesions & Frequency (\%) \\
\hline Mitral stenosis only & $9(42.9)$ \\
Mitral regurgitation only & $6(28.6)$ \\
Aortic stenosis only & $1(4.8)$ \\
Aortic regurgitation only & $1(4.8)$ \\
Mitral regurgitation + aortic regurgitation & $1(4.8)$ \\
Mitral stenosis + aortic regurgitation & $1(4.8)$ \\
Mitral regurgitation + mitral stenosis & $1(4.8)$ \\
Aortic regurgitation + aortic stenosis & $1(4.8)$ \\
\hline
\end{tabular}


of our knowledge, there is no community screening study of rheumatic heart disease in Cameroon. Echocardiographic screening studies of rheumatic heart disease in Africa have shown that the prevalence was $1.5 \%$ among school children in Uganda, $3 \%$ in Mozambique and $0.75 \%$ in Senegal [15-17]. The majority of patients in our study were referred for echocardiography following a clinical diagnosis of heart failure. Studies in Africa have shown that rheumatic heart disease is one of the dominant causes of heart failure. In the THESUS-HF registry of 1006 patients with heart failure from nine countries, RHD was the third most important cause of heart in adult Africans after hypertension and cardiomyopathies [5]. It is possible that the true prevalence of RHD in the community is higher as symptomatic patients are more likely to seek medical attention. Echocardiography has been shown to be superior to auscultation in the diagnosis of rheumatic heart disease. Widespread use in high prevalence settings is limited by cost and scarcity of skilled personnel.

The mitral valve was the most commonly affected valve in our study. This pattern of involvement is similar to that from other developing countries where the order of involvement is mitral followed by aortic, tricuspid and pulmonic valves [14]. This same pattern was reported in previous studies from other parts of Cameroon [13, 18]. Isolated mitral stenosis was the most common rheumatic lesion in our study (42.9\%). This was different from reports from other parts of the country where the predominant rheumatic valve lesion was mitral regurgitation $(49.2-59.7 \%)$ [13, 17]. The reason for this could not be ascertained. In Nigeria, Sani et al. also reported a predominance of mitral regurgitation in the Nigerian savannah [14]. Pulmonary hypertension was present in $66.7 \%$ of the patients in our study. This is in agreement with findings from local studies in Cameroon $[13,18]$. About $10 \%$ of the patients presented with atrial fibrillation. Rheumatic heart disease is a major cause of atrial fibrillation in high endemic regions of the world. Rheumatic heart disease was the cause of atrial fibrillation in $25.6 \%$ of patients with atrial fibrillation in Yaounde [19]. The majority of the patients in our study presented with severe valvular lesions. The treatment of advanced rheumatic heart disease is usually surgical. But the cost of cardiac surgery usually makes this treatment procedure unaffordable to most families in resource limited settings like ours.

Our study has shown that rheumatic disease is still common in our setting with the majority of patients presenting with severe disease. There should be renewed emphasis on the prevention of this neglected disease.

\section{Limitations}

This study was a hospital based review hence subject to bias. Our sample has potentially included patients with more symptomatic lesions since it was at a referral institution. Secondly, patients referred for echocardiography may be those with more severe rheumatic heart disease as patients with more severe lesions are more likely to seek medical attention. Despite this limitation, our study is the first to report on the pattern of rheumatic heart disease in this part of the country.

\section{Abbreviations \\ ACC: American College of Cardiology; AHA: American Heart Association; ARF: acute rheumatic fever; RHD: rheumatic heart disease; THESUS-HF: the sub- Saharan Africa survey of heart failure; WHF: World Heart Federation. \\ Authors' contributions \\ $C N, A D, C M, L E B, A J$ designed the study. CN performed the echocardiograms, collected the data, analyzed the data and drafted the initial version of the manuscript. CM, AD, AJ and SK critically reviewed the manuscript. All authors read and approved the final manuscript.}

\section{Author details}

${ }^{1}$ Buea Regional Hospital, Buea, South West Region, Cameroon. ${ }^{2}$ Faculty of Medicine and Biomedical Sciences, University of Yaounde 1, Yaounde, Cameroon. ${ }^{3}$ Douala General Hospital, Douala, Cameroon. ${ }^{4}$ Athena Institute for Research on Innovation and Communication in Health and Life Sciences, Vrije Universiteit, Amsterdam, The Netherlands.

\section{Acknowledgements}

None.

Competing interests

The authors declare that they have no competing interests.

Availability of data and materials

The datasets used and/or analyzed during the current study are available from the corresponding author on reasonable request.

\section{Consent for publication}

Not applicable.

\section{Ethical approval and consent to participate}

The study was approved by the administrative authorities of the Buea Regional Hospital. This study reviewed cases of rheumatic heart disease retrospectively and as such no individual consent was obtained from the participants.

\section{Funding}

The authors did not receive any funding for the study.

\section{Publisher's Note}

Springer Nature remains neutral with regard to jurisdictional claims in published maps and institutional affiliations.

Received: 7 August 2017 Accepted: 30 March 2018

Published online: 03 April 2018

References

1. Carapetis JR, McDonald M, Wilson NJ. Acute rheumatic fever. Lancet. 2005;366(9480):155-68.

2. Carapetis JR, Steer AC, Mulholland EK, Weber M. The global burden of group A streptococcal diseases. Lancet Infect Dis. 2005;5(11):685-94. 
3. Marijon E, Mirabel M, Celermajer DS, Jouven X. Rheumatic heart disease. Lancet. 2012;379(9819):953-64.

4. Essop MR, Nkomo VT. Rheumatic and nonrheumatic valvular heart disease: epidemiology, management, and prevention in Africa. Circulation. 2005;112(23):3584-91.

5. Damasceno A, Mayosi BM, Sani M, Ogah OS, Mondo C, Ojji D, et al. The causes, treatment, and outcome of acute heart failure in 1006 Africans from 9 countries. Arch Intern Med. 2012;172(18):1386-94.

6. Ogah OS, Adegbite GD, Akinyemi RO, Adesina JO, Alabi AA, Udofia Ol, et al. Spectrum of heart diseases in a new cardiac service. In Nigeria: an echocardiographic study of 1441 subjects in Abeokuta. BMC Res Notes. 2008;1:98.

7. Ike SO. Echocardiographic analysis of valvular heart diseases over one decade in Nigeria. Trans R Soc Trop Med Hyg. 2008;102:1214-8.

8. Adebayo RA, Akinwusi PO, Balogun MO, Akintomide AO, Adeyeye VO, Abiodun OO, et al. Two-dimensional and Doppler echocardiographic evaluation of patients presenting at Obafemi Awolowo University Teaching Hospitals complex, lle-lfe, Nigeria: a prospective study of 2501 subjects. Int J Gen Med. 2013;6:541-4.

9. James OO, Efosa JD, Romokeme AM, Zuobemi A, Sotonye DM. Dominance of hypertensive heart disease in a tertiary hospital in southern Nigeria: an echocardiographic study. Ethn Dis. 2012;22:136-9.

10. Sadoh WE, Omuemu VO, Israel-Aina YT. Prevalence of rheumatic heart disease among primary school pupils in mid-western Nigeria. East Afr Med J. 2013;90:21-5.

11. Remenyi B, Wilson N, Steer A, Ferreira B, Kado J, Kumar K, Lawrenson J, Maguire G, Marijon E, Mirabel M, et al. World Heart Federation criteria for echocardiographic diagnosis of rheumatic heart disease-an evidencebased guideline. Nat Rev Cardiol. 2012;9(5):297-309.
12. Nishimura RA, Otto CM, Bonow RO, Carabello BA, Erwin JP 3rd, Guyton RA, O'Gara PT, Ruiz CE, Skubas NJ, Sorajja P, et al. 2014 AHA/ACC guideline for the management of patients with valvular heart disease: executive summary: a report of the American College of Cardiology/American Heart Association Task Force on Practice Guidelines. Circulation. 2014;129(23):2440-92.

13. Nkoke C, Lekoubou A, Dzudie A, Jingi AM, Kingue S, Menanga A, Kengne AP. Echocardiographic pattern of rheumatic valvular disease in a contemporary sub-Saharan African pediatric population: an audit of a major cardiac ultrasound unit in Yaounde, Cameroon. BMC Pediatr. 2016;21(16):43. https://doi.org/10.1186/s12887-016-0584-z.

14. Sani MU, Karaye KM, Borodo MM. Prevalence and pattern of rheumatic heart disease in the Nigerian savannah: an echocardiographic study. Cardiovasc J Afr. 2007;18(5):295-9.

15. Beaton A, Okello E, Lwabi P, Mondo C, McCarter R, Sable C. Echocardiography screening for rheumatic heart disease in Ugandan schoolchildren. Circulation. 2012;125(25):3127-32.

16. Grimaldi A, Ammirati E, Mirabel M, Marijon E. Challenges of using ultrasounds for subclinical rheumatic heart disease screening. Int J Cardiol. 2013;167(6):3061.

17. Kane A, Mirabel M, Toure K, Perier MC, Fazaa S, Tafflet M, Karam N, Zourak I, Diagne D, Mbaye A, et al. Echocardiographic screening for rheumatic heart disease: age matters. Int J Cardiol. 2013;168(2):888-91.

18. Tantchou Tchoumi JC, Butera G. Rheumatic valvulopathies occurence, pattern and follow-up in rural area: the experience of the Shisong Hospital, Cameroon. Bull Soc Pathol Exot. 2009;102(3):155-8.

19. Ntep-Gweth M, Zimmermann M, Meiltz A, Kingue S, Ndobo P, Urban P, Bloch A. Atrial fibrillation in Africa: clinical characteristics, prognosis, and adherence to guidelines in Cameroon. Europace. 2010;12(4):482-7.

\section{Submit your next manuscript to BioMed Central and we will help you at every step:}

- We accept pre-submission inquiries

- Our selector tool helps you to find the most relevant journal

- We provide round the clock customer support

- Convenient online submission

- Thorough peer review

- Inclusion in PubMed and all major indexing services

- Maximum visibility for your research

Submit your manuscript at www.biomedcentral.com/submit
O Biomed Central 